\title{
La crisis del poeta moderno en El blasfemo coronado de Humberto Díaz-Casanueva. La dialéctica entre razón filosófica y delirio poético ${ }^{1}$
}

\section{The Crisis of the Modern Poet in Humberto Díaz-Casanueva's El Blasfemo Coronado. Dialectics Between Philosophical Reason and Poetic Delirium}

\author{
MICAELA PAREDES BARRAZA \\ New York University, Department of Spanish and Portuguese Languages and Literatures. \\ Estados Unidos. Correo electrónico: mpb472@nyu.edu
}

En el presente trabajo analizo el poema en prosa El blasfemo coronado (1940) de Humberto DíazCasanueva. En este poema se reconoce la construcción de una visión particular de la figura del poeta y el rol que cumple su palabra en el contexto de la modernidad. En la obra se enfrentan una serie de tensiones, expresadas no solo a nivel temático sino también formal. Las dualidades desplegadas en el texto forman parte del conflicto existencial de un hablante que se encuentra escindido en dos actitudes aparentemente irreconciliables: el raciocinio filosófico y el delirio poético.

Palabras clave: Humberto Díaz-Casanueva, El blasfemo coronado, filosofía, poesía, poema en prosa, racionalidad moderna.

In this paper I analyze Humberto Díaz-Casanueva’s prose poem El blasfemo coronado (1940). The poem points out a particular construction of the poet's figure and the role his words play in the context of modernity. A set of tensions are expressed both at the thematic and formal levels. The dualities displayed in the text are part of the subject's existential conflict. The poetic voice is split into two apparently irreconcilable attitudes: philosophical reason and poetic delirium.

Key words: Humberto Díaz-Casanueva, El Blasfemo Coronado, philosophy and poetry, prose poem, modern rationality.

\footnotetext{
${ }^{1}$ Este trabajo es parte del proyecto de investigación Fondecyt No 1150535: "Poema en prosa y modernidad en Chile: del modernismo a la vanguardia (1888-1945)”. Investigador a cargo: Patricio Lizama.
} 


\section{INTRODUCCIÓN}

La obra de Humberto Díaz-Casanueva se caracteriza por la consistencia y continuidad de los motivos centrales que la hacen surgir. Desde su segundo libro, Vigilia por dentro (1931), asistimos al despliegue de un camino bastante homogéneo en cuanto a los temas tratados y al tono con que se abordan. Una posible lectura, que es por la que aquí optamos, es la de reconocer la presencia de un solo sujeto lírico que, a través de los diferentes poemarios, da cauce a sus diferentes voces, facetas y etapas, en una travesía que apunta hacia un gran y último propósito: llegar a comprender los fundamentos últimos de la existencia, con la intuición de que en ella opera una potencia superior que sostiene a la vez que trasciende al ser individual.

En este trabajo se emprende una lectura del tercer libro del autor, El blasfemo coronado (1940), poema en prosa de largo aliento separado en partes numeradas. El análisis parte del reconocimiento de que en esta obra se construye una visión particular de la figura del poeta y del rol que cumple su palabra en el contexto de la modernidad. A través del poema en prosa, género moderno concebido como espacio textual dialógico y antitético, se da cauce a un conflicto existencial y poético que reconocemos como la escisión del hablante en dos polos, a los que podemos identificar como razón e intuición y que se expresan como inquietud filosófica y aprehensión poética respectivamente.

\section{Aproximaciones críticas a El Blasfemo Coronado}

La mayor parte de la crítica concuerda en reconocer como eje articulador de la obra la problemática identitaria, de orden existencial-ontológico, que padece el hablante lírico. Nómez (1992) lo define como la "búsqueda de una revelación sagrada a través de un desgarramiento del Yo que busca su identidad mediante la palabra y la creación" (196). Foxley (1998) plantea la existencia de dos voces; no como dos personas distintas, sino como dos dimensiones de un solo sujeto que sufre una "disociación discursiva en la persona del yo reflexivo y visionario" (28). Por su parte, Schwitzer (1967) lo concibe como la dicotomía entre mismidad y otredad a la que se ve enfrentado el hablante; individualidad que representa el drama vivido por el hombre universal en su lucha por "salvaguardar su 'yoesencia' y protegerlo del 'yo-otro'” (182).

A esta primera dualidad se le suman otras, que operan a distintos niveles, se cruzan e implican. Foxley (1998) señala que el poema inicia con el planteamiento de una contradicción entre el anhelo de un conocimiento acabado, que no es posible alcanzar, y la posesión efectiva de recursos irracionales como la intuición. Esta antítesis entre razón e intuición se traduce en la existencia de dos lenguajes distintos. Elliot se refiere a ellos como "la noesis reflexiva y la sensibilidad emotiva" (citado en Rojas 1992: 52), en concordancia con Minard (1988), quien plantea la dicotomía en términos de palabra común y palabra poética. A esta última Schwitzer (1967) la relaciona con la dimensión onírica y la pondera 
como único recurso posible para acceder al misterio que palpita bajo la realidad concreta. El sujeto desea alcanzar la "síntesis entre la sinceridad de la expresión lírica y el pensamiento abstracto en un esfuerzo definitivo por definir las cuestiones del existir del hombre" (182).

Del Valle (1959) hace hincapié en el carácter pesimista que impregna la vivencia total del sujeto poético: "[la] blasfemia actual es, pues, este viaje continuo hacia la soledad, esta visita a los enigmas" (69). El estado de soledad del sujeto, plantea Foxley (1998), no llega a superarse hacia el final del poema: culmina con el anhelo de unidad no alcanzado y con la consecuente conciencia del protagonista de su "impotencia y empequeńecimiento" (29). Sin embargo, según Elliot, aunque el sujeto asume su incapacidad y no logra asir el sentido último de su existencia, hay un sentimiento místico latente; el vislumbre de una trascendencia que no llega a ser nunca visión reveladora (Rojas 1992).

En síntesis, verificamos la existencia de una serie de dualidades en tensión. $E l$ blasfemo coronado es un texto en que la dialéctica opera a diferentes niveles y de forma simultánea: a través de la lectura, asistimos a la incesante lucha en que se debaten pares de fuerzas contrarias: "lo eterno y el instante, la esencia y la caducidad, el yo y el prójimo, la luz y la sombra, la muerte y la vida, el sueño y lo real, el gozo y el dolor" (Jiménez 1981: 89).

Sin embargo, hasta el momento sólo se ha identificado cómo la dialéctica opera a nivel temático, pero no se ha reparado en un aspecto fundamental, que salta a la vista antes de emprender cualquier lectura: el género en el que se inscribe el texto. Como ya se mencionó, estamos ante un poema en prosa. Este género, o antigénero, como también se le ha denominado por la dificultad que presenta para fijar sus características y límites, nace en la modernidad y ha sido definido en sí como dialéctico, ya que se configura como un espacio textual que alberga en su seno una serie de contradicciones.

\section{EL POEMA EN PROSA: GÉNERO MODERNO}

El poema en prosa ha sido descrito como un género literario híbrido en el que convergen dos lenguajes: el prosaico y el lírico. La tensión que se produce entre ambas formas disímiles de expresión es "síntoma de su modernidad" (Utrera 1999: 12). Lo moderno, según Paz (1974), se caracteriza no sólo por su novedad, sino también por su heterogeneidad: la tradición moderna es una antitradición, en la que lo único constante es el cambio. El poeta mexicano reconoce que el motor de la época moderna, de su devenir histórico y artístico, es la crítica: ejercicio analítico que apunta, antes que nada, contra sus propios mecanismos de funcionamiento.

Será Baudelaire quien instalará el poema en prosa como género moderno propiamente tal, trazando las directrices de sus posibilidades, propósitos y organización formal. Si bien el primer antecedente es Aloysius Bertrand y su Gaspard de la nuit, es Baudelaire quien se apropia del género y le infunde el elemento moderno, así como más tarde Rimbaud le otorgará una gramática nueva (Guillaume en Jiménez Arribas 2005). Los Petits poèmes en prose de Baudelaire presentan una estructura particular en la que todo 
“es pies y cabeza a la vez, alternativa y recíprocamente" (Baudelaire en Millán 1989: 33). Como explica Utrera (1999), el conjunto de pequeños fragmentos se presenta como "una totalidad, cuyo orden interno no obedece a la continuidad narrativa o argumental, sino a la similitud y armonía entre los textos del grupo, de modo que cada uno de ellos puede servir tanto de principio como de final" (81). Este aspecto es de gran relevancia para el análisis que emprenderemos de El blasfemo coronado, ya que, al presentar esta misma estructura flexible, acepta diferentes modos de lectura. Abordarlo fragmentariamente, como nos proponemos hacer aquí, no implica violentar el texto ni forzar sus posibles sentidos. Esto concuerda con la concepción baudelaireana de la creación poética como analogía del sistema del universo.

En el poema en prosa, al no haber una estructura formal a priori, como en el caso, por ejemplo, de la versificación métrica, la organización surge "desde dentro, basada en la forma interior" (Utrera 1999: 14)². No hay separación entre unidad formal y unidad espiritual: todo en el texto está íntimamente ligado, de manera que la unidad expresiónexperiencia "supone una revelación ontológica de naturaleza trascendente, la sinceridad y el fondo subjetivo" $(14)^{3}$. Se puede afirmar, entonces, que la convivencia que se da al interior del poema en prosa de elementos disímiles — prosaísmo y lírica, razón crítica y delirio poético, lo cotidiano y lo sobrenatural, la ironía y la angustia, lo bello y lo grotesco, escepticismo y sentimiento religioso- no es otra cosa que la plasmación de la naturaleza contradictoria de la existencia y el anhelo de superarla en el cese de la diferencia. Como lo expresa Aullón de Haro (2005), el poema en prosa "representa una idealidad como aspiración a la síntesis" (25).

En el caso de El blasfemo coronado, veremos que la apertura e incorporación de otras categorías discursivas se plasma principalmente como reflexión filosófica y metaliteraria. Esto, sin embargo, no va en detrimento de la experiencia poética, que es la forma primaria de aprehensión del drama existencial que se plasma en el poema. Filosofía y metapoesía no aparecen como teorización abstracta, sino como parte del cuestionamiento vital del hablante enfrentado a su destino. En este sentido, reconocemos un motivo similar al que Utrera identifica en los Himnos a la noche de Novalis, antecedente del poema en prosa, en los que se busca "desarrollar alegóricamente el viaje simbólico interior del individuo en busca de la verdad y de la luz" (47).

\footnotetext{
${ }^{2}$ Las cursivas son originales del texto.

${ }^{3}$ La importancia que adquiere el despliegue de la subjetividad en el poema en prosa se relaciona directamente con la conciencia moderna del desgarro. El hecho de saberse solo, separado del resto de lo existente, impulsa al hombre moderno a querer recuperar la perdida unidad; alimenta su deseo de reintegración al Todo al que originariamente perteneció. El gran distintivo moderno es que ese deseo de semejanza no es un retorno a la inocencia, sino un proceso sólo posible a través de la voluntad, de la conciencia que se hace consciente de sí misma y de su naturaleza incompleta.
} 


\section{Poesía y FiLosofía: Dos Caminos divergentes}

A lo largo de los fragmentos que constituyen El blasfemo coronado, se despliega una lucha entre dos visiones de mundo aparentemente irreconciliables en el camino hacia la verdad: razón filosófica y delirio poético. Este enfrentamiento es expresión indiscutible de la crisis espiritual que genera en el interior del hombre la imposición racional del pensamiento moderno, el que surge y se desarrolla a partir de la confianza ciega, casi religiosa — lo que constituye su mayor paradoja - en la autosuficiencia de la razón como principio fundador y absoluto. De esta manera, el conflicto vital del sujeto poético puede entenderse como producto de la escisión interior entre el principio racional, rector del devenir individual y colectivo, y todas aquellas otras facultades renegadas que se identifican bajo el rótulo general de potencias irracionales.

Para María Zambrano (2013), estos dos paradigmas se corresponden con la figura del filósofo y la del poeta respectivamente. Según la filósofa española, "pensamiento y poesía se enfrentan con toda gravedad a lo largo de nuestra cultura. (...) Se nos aparecen como dos formas insuficientes; y se nos antojan dos mitades del hombre: el filósofo y el poeta" (13). El reconocimiento de estas dos mitades no se reduce tan solo a una categorización de dos tipos de discurso teórico-abstractos divergentes, uno relativo a los sujetos que hacen filosofía y otro a aquellos que escriben poemas, sino que se plantean en un sentido amplio como dos actitudes esenciales; dos impulsos vitales de los que es capaz todo ser humano en cuanto tal ${ }^{4}$.

El camino de aprehensión de la realidad interna y externa se lleva a cabo a través del lenguaje: la palabra tiene un rol fundamental en el camino de desentrańamiento del ser en tanto juega un papel mediador; es el espacio en el que lo informe toma forma y los acontecimientos se transforman propiamente en experiencia. La encarnación en la palabra "tiene lugar mediante esa doble actitud del poeta y del filósofo, a medio camino entre la verdad (unidad) hallada sin previa pregunta del primero y la verdad (unidad) buscada del segundo" (Maillard 1992: 34). Estas dos formas de buscar y entender la verdad surgen de dos actitudes divergentes: la extrańeza y el asombro.

El filósofo se extrańa. El enigma en que se funda la existencia de las cosas lo impulsa a buscar respuestas, a tratar de aprehender el fundamento último que sostiene la realidad en su multiplicidad de manifestaciones, incluido su propio ser. En el momento en que comienza el extrañamiento, el sujeto "empieza a padecer su falta de unidad" (Maillard 33), se sabe distinto de todo lo que lo rodea. Por eso Zambrano afirma que la filosofía

\footnotetext{
${ }^{4}$ En su libro Filosofía y poesía, la autora se dedica a rastrear y caracterizar el recorrido histórico del pensamiento occidental desde Platón — primero en establecer la división y condenar a la poesía como práctica ilegítimahaciendo mención directa a épocas, autores y discursos filosóficos determinados. No obstante, explica que esta división entre el discurso filosófico y el poético, que a lo largo del tiempo se ha materializado en obras culturales concretas, tiene su raíz, antes que nada, en el interior de cada hombre: filosofar y poetizar son dos formar de estar en el mundo, de interactuar con y en él. Cada una de estas posibilidades de lo humano se manifiesta en el lenguaje; no necesariamente bajo la forma de tratados filosóficos y poemas, sino como dos formas diferentes de establecer relaciones y crear sentidos.
} 
lleva el signo de la violencia: la distancia impuesta por el pensamiento es un desgarro; reconocimiento de la diferencia sustancial entre las cosas y la conciencia que las nombra en su intento de comprenderlas.

El poeta, en cambio, se asombra. Se deja invadir por el misterio que lo asalta; entra en comunión, a través del éxtasis, con la totalidad de lo existente; no como unidad abstracta sino como materialidad palpable. La poesía persigue "la multiplicidad desdeñada, la menospreciada heterogeneidad" (Zambrano 2013: 19). En este sentido, el poeta desde un comienzo se asume como parte de algo mayor que trasciende su individualidad y que constituye un misterio que no le es dado descifrar.

Esta noción de la poesía como una verdad velada que el poeta no crea, sino que recibe, se condice con la forma en que Heidegger pondera el fenómeno poético, cuando afirma que "todo arte, como advenimiento de la verdad, es en su esencia misma poesía" (2014: 111). Desde esta perspectiva, la poesía es un fenómeno que existe no solo como actividad humana al interior de un mundo ya acabado, determinado a priori, sino como actividad ontológica, determinante en el proceso mismo de crear ese mundo, esa realidad. Las instancias de manifestación del ser se denominan aperturas y la relación que establecen con el hombre es dialéctica: existe una dinámica de apropiación-expropiación, en el sentido de que "el hombre encuentra siempre esas aperturas como dadas, por un lado; pero por otro, también contribuye a determinarlas" (Vattimo 1998: 104). Estos dos movimientos necesarios para la apertura encuentran su correlato con esas dos actitudes esbozadas por Zambrano: por un lado, la voz del filósofo y la confianza en su voluntad para asir la verdad y, por otro, la voz de poeta como el que se pone a disposición de una voluntad otra para recibir esa verdad.

Ahora bien, la naturaleza de dicha verdad se aleja de la concepción tradicional e ilustrada del término como una relación de conformidad entre la preposición y el ente al que designa, es decir, de referencialidad. Heidegger vuelve al origen del concepto, a la palabra en griego $a$-letheia, en la que esa $a$ privativa indica que la verdad, al mismo tiempo que se manifiesta como revelación, "presupone un esconderse, un ocultarse originario" (Vattimo 73). En este sentido, la esencia misma de la verdad es dialéctica. El punto de partida para el análisis de El Blasfemo, entonces, es el reconocimiento que el conflicto existencial del sujeto poético gira en torno a esa continua tensión entre los momentos de revelación y su posterior vuelta a las sombras.

\section{Análisis de El BLasfemo Coronado}

\subsection{Crisis de la racionalidad moderna}

El hablante de El blasfemo coronado asiste a la desintegración de su identidad, eje articulador de la realidad desde una perspectiva moderna. La subjetividad es el centro desde el que opera la facultad racional, que codifica y ordena el mundo sistemáticamente 
con la pretensión de alcanzar un conocimiento acabado, definitivo. La irrupción de potencias extrańas e incontrolables genera en el hablante una crisis existencial, a partir de la que comienza a preguntarse de dónde proviene aquella otra dimensión hasta ahora no contemplada por la razón:

Pero hay un fin en mí que ignoro, una rueda oscura que me expande. ¿Seré acaso una aparición de mí mismo? (...)

Pero yo quisiera constituirme, ser tan real, tan duro y silbando impedir que la noche madure en mí burlona, sentirme en mi cuerpo más que en mi alma y tenderme como un esposo, en un solo lecho sin la lanza hundida en el costado (Díaz-Casanueva 1981: IV, 17).

El yo reconoce la existencia de un propósito mayor que lo trasciende, pero se niega a abandonar el deseo de poseerse a sí mismo. En este pasaje, la esperanza de constituirse como un ente real apunta a una vivencia plena de lo material, a una armonía con el entorno. La metáfora del esposo se resuelve unas líneas más adelante, cuando el hablante explicita su deseo frustrado de fundirse con la naturaleza: "Ah loca naturaleza, estás lejos de ser mi esposa!" (IV, 18). Reconocemos aquí un tópico que surge con fuerza en la poesía romántica y que apunta directamente a evidenciar el conflicto del hombre moderno, sometido al yugo de la razón, escindido en su interior. Casullo (1999) se refiere a esta problemática aludiendo específicamente a la poesía de Hölderlin, una de las influencias determinantes en Díaz-Casanueva. Para el poeta alemán, "la modernidad es el tiempo que pone en definitiva evidencia que el hombre ha sido separado de los dioses. Por lo tanto, ha sido expulsado de la armonía de la naturaleza. Ha sido hachado en dos, alma y mente. Ha extraviado su historia" (Casullo 1999: 281).

En el caso de El blasfemo, el hablante oscila entre dos extremos en su intento de subsanar la escisión, ambos infructuosos. Uno es el recién mencionado deseo de retorno a la naturaleza, el que se sabe imposible desde el principio, pues la inocencia original se ha perdido para siempre. El segundo, en el que se empeñará arduamente, es el afán de entendimiento racional: "Quisiera beberme hacia adentro, mas el vaso está demasiado ardiente, quisiera comprender con la voluntad, afirmar con los actos, pero convierto al suelo en un dolor agudo, a la mujer en un silbato de plata ronco" (Díaz-Casanueva 1981: IV, 18). Los dos elementos mencionados, el suelo y la mujer, representan dos puntos de contacto con el misterio. La tierra y el cuerpo femenino son fecundadores de vida, fuentes del origen, pero el hablante es incapaz de conectarse con aquella dimensión, de descifrarla de forma correcta:

Como el que pregunta en sueños y no es entendido, como el que oye un lebrel ronco que araña debajo de la tierra y dice mentira y obtiene por renombre lo inexistente (...) así voy en pos de los terribles signos, así estoy y humillo mis propias acciones y quiebro mi coraza para que me juzguen (VIII, 31). 
El sujeto se siente llamado a cumplir con una misión importante, a descifrar los signos del destino y ser capaz de penetrar en el misterio último de todo lo que es. Su error está en el camino que escoge para llevar a cabo esa tarea. El anhelo de comprensión que manifiesta el yo poético responde al paradigma moderno de la autosuficiencia: el hombre quiere encontrar "por sí el ser y su ser. En suma [salvarse] a sí mismo con su decisión (Zambrano 2013: 41). Frente al fracaso, el yo se sume en un estado de frustración e impotencia que se instala como atmósfera general del mundo poético desplegado.

La gran disyuntiva a la que el hablante se enfrenta surge de la toma de conciencia de la esterilidad de su razón. Aun evidenciando que su método de aprehensión es insuficiente, el hablante se niega a abrirse a otras formas del saber: "La locura enterrada es el orden de los hados, yo pretendo causas absolutas, quiero ser mío ásperamente, procrearme con un poco de paciencia pero sabiéndolo" (Díaz-Casanueva 1981: IX, 35). Este pasaje es crucial, pues en él se menciona de manera explícita la locura como potencia conductora del destino. Si bien el reconocimiento del importante rol que cumple el delirio constituye un primer paso en el camino que emprende el hablante hacia la integración, enseguida retrocede y vuelve a afirmar su lealtad a la razón y a la idea de una verdad absoluta. En este sentido, a pesar de su deseo de conciliación con la naturaleza, su temor a ir más allá de su zona de seguridad lo hace seguir perpetuando una visión limitada que "(...) segrega en dos mundos escindidos y contradictorios la verdad y el error, el ser y el no-ser, como dos absolutos que no admiten matizaciones, interferencias o penumbras" (Ortega 2007: 16).

Frente al recelo del yo, que no se atreve a renunciar a su anhelo de control, es que surge el yo-otro, como posibilidad de apertura a un modo más amplio de comprensión:

Noche y día te tiende dulces lazos, fatales delirios, cabalgas un lecho alado. Pero gloria a la vida terrenal, es efimera y nunca colmada y sólo asi es verdadera. (...) pero no nos oyes, ah sabedor que espesas tu crecimiento, inspirado gris, tu dedo pones sobre las cosas y las desvastas [sic] de su sentido verdadero, la dulce materia espantas a grandes gritos $^{5}$ (VI, 26).

La concepción poética que plantea el yo-otro rompe los esquemas del yo y su inquietud filosófica. Ambas aproximaciones al mundo se plantean como dos formas incompatibles de entender 'la verdad'. El yo, al desconfiar de las cosas en su inmediatez y lanzarse a la búsqueda platónica de las Ideas, pretende "salvarse de las apariencias" (Zambrano 2013: 20): “(...) calmaré los secretos cuyo litigio se libra con los abismos mientras el hombre aguarda de pie. Todo eso ansío conforme a lo sembrado, anclas desgarro en todas partes ¿puedo llegar a poseer el fin de todo?" (Díaz-Casanueva 1981: IX, 35-35). Como plantea Ortega (2007), la idea de alcanzar la esencia que se oculta tras lo aparente

${ }^{5}$ Las cursivas son originales del texto. Todos los fragmentos en este formato corresponden a los pasajes en que habla el yo-otro. 
implica la premisa de que es posible establecer una distinción entre lo verdadero y lo falso. Por su parte, el yo-otro "no cree en la verdad, en esa verdad que presupone que hay cosas que son y cosas que no son" (Zambrano 2013: 24); para él todo es.

Las apariencias, si es que cabe llamarlas así, son parte de la gran unidad en la que están contenidos ser y no ser, vida y muerte. De ahí el llamado a celebrar lo efímero de la vida. Que esta no esté nunca colmada no significa que sea precaria o insuficiente, sino que es en esencia devenir. Como expresa Miguel Guezález en su análisis del poema, el yo-otro encarna un impulso esencial "cuyo valor radica en el puro trascender" (1949: 94). Es decir, en un ir más allá de sí: despliegue cuyo propósito no es alcanzar un punto de término sino la realización misma del movimiento.

En síntesis, el yo-otro con su don, con su amplitud de visión, ofrece la posibilidad de subsanar la escisión que padece el yo, abriéndole un camino nuevo, diferente al racional, para reconciliar los opuestos. El viaje simbólico que emprende el hablante a lo largo de todo el poema es hacia su propio interior, al encuentro con una parte desconocida de él mismo que lo conecta con los misterios del ser. Los obstáculos que surgen en el camino no son más que estertores de su propia consciencia, que retrocede frente al "peligro que se corre en la empresa. ¿Cuál peligro? ir más allá de la razón, escalar ese sentimiento de infinito perteneciente a los dioses" (Casullo 1999: 285). Si bien el hablante en ningún momento logra la síntesis definitiva de las dos naturalezas opuestas que constituyen su esencia, sí lucha permanentemente por alcanzarla. Así, pasa de la negación rotunda a ceder ante el anhelo de experimentar aquella dimensión otra y dejarse invadir por sus enigmas:

Pero las disputas al interior de mi ser (...) y muchas otras cosas más que a mis espaldas suceden, me impiden cumplir mi entendimiento.

Disponedme entonces a las secretas nupcias, dadme cantos, dadme cuernos que no se cansen de perseguir, dadme el corazón degollado por los enemigos.

¿No véis que soy un brujo que tantea con su tirso a los vivos y muertos y que tarda en separarlos completamente? (X, 40-41).

Ahora bien, el hecho de abrirse al misterio en ningún caso se presenta como solución o cese definitivo del sufrimiento. Por el contrario, cuando el sujeto poético acepta la existencia de una potencia irracional que pide manifestarse a través de su persona, la frustración, la angustia y la desolación se radicalizan: el hablante está destinado a ser el medio de manifestación de una fuerza que excede su limitada condición humana.

\subsection{El don profético}

"Yo nada sé, yo tiemblo apenas y uñas se me clavan buscando lugar. Algo en mí parpadea y se despeña como crecida de río salvaje" (Díaz-Casanueva 1981: XII, 47). 
Los momentos en que el sujeto poético renuncia a su entendimiento y asume, en sintonía con una visión romántica, que "la liberación ya no es posible a través de lo solamente humano" (Casullo 1999: 281), comienza a padecer una angustia de otra naturaleza: ya no la de sentirse incompleto por falta de respuestas, sino que, por el contrario, excedido, poseído por una potencia misteriosa que supera sus capacidades. Esta es, en palabras de Zambrano, la crisis propia del poeta, quien, considerado como un ser especial, está destinado llevar a cabo una misión que no comprende: "el poeta tiene lo que no ha buscado y más que poseer, se siente poseído" (41). La idea de la posesión por una fuerza superior aparece en varias ocasiones a lo largo del texto: "Soltadme seres de la embriaguez primordial, restituidme al dulce tiempo humano" (Díaz-Casanueva 1981: XXI, 77).

El fenómeno al que se ve sometido el sujeto poético se caracteriza por dotarle de la facultad de 'ver más allá que el resto de los hombres. Es decir, lo convierte en vidente. La identificación del poeta con esta figura tiene una larga tradición y es caracterizada por Selena Millares, en términos generales, como un don profético a través del que el poeta es "capaz de desentrañar los misterios del universo y de leer sus claves sagradas" (2008: 30). Un aspecto que resalta la autora es que lo profético no se vincula necesariamente con el futuro, sino con la penetración en el presente y en la esencia profunda de las cosas.

Comprobamos que en varios momentos el yo de El blasfemo utiliza palabras asociadas al sentido de la vista: "Ayúdame a poseer la tierra, oh visión que manas de mi propia sangre! $(\mathrm{X}, 40)$; “Todo está dentro de mí y excede mi memoria, / da vueltas mi perfil enronquecido de uno a otro confín como si buscara un espejo donde se fraguan imágenes eternas" (XX, 73). En los dos fragmentos anteriores se hace hincapié, además, en esa potencia desconocida de naturaleza trascendente, representada en un otro, en última instancia no es sino parte esencial de la mismidad. Es la fuerza primigenia que hace posible la existencia del sujeto como individuo y que al mismo tiempo lo instala dentro de una totalidad mayor.

Un aspecto que resaltar es que, para dar cuenta de aquella dimensión trascendente que lo habita, en más de una ocasión el yo se vale de la imagen del rayo: “(...) relámpagos miran dentro de mí, conmigo están el primer hombre y también el último hombre, ambos hincados y temblando" (III, 14-15); "Entra un rayo lustral a mi semblante. Ah rayo, permanecer esta noche conmigo! (IV, 18). Estos fragmentos evocan al ya mencionado Rubén Darío y su poema “¡Torres de Dios! ¡Poetas! / ¡Pararrayos celestes, / que resistís las duras tempestades, / (...) rompeolas de las eternidades!” (2009: 105), como también remiten a la aseveración hecha por Heidegger: "El poeta está expuesto a los relámpagos de Dios" (2014: 118). Esta particular ponderación del poeta como canalizador, lo instala en una posición superior al común de los hombres: el poeta es el elegido para transmitir un mensaje de naturaleza sobrehumana. La forma en que el hablante asume este rol se caracteriza por dos aspectos que precisaremos a continuación. Primero, el poder que se le otorga es sentido, más que como don, como un castigo. En segundo lugar, y en relación directa con lo anterior, el cumplimiento de la tarea profética impuesta exige una actitud de sumisión y sacrificio.

Respecto a la valoración negativa que el sujeto hace de su don, la principal forma en que se manifiesta es a través de la negación: "Ah poderes que continuamente estáis 
engendrándome, me tapo los ojos para que la blanca candela que movéis entre los muertos no me guíe de día (...)" (Díaz-Casanueva 1981: III, 13). Se presenta aquí una paradoja: la luz guía que lo convoca no está asociada, en este pasaje específico, al cielo ni al ámbito de lo sagrado, sino que proviene del oscuro mundo de los muertos, desde un más allá tenebroso que produce rechazo. El hecho de no poder eludir esta luz oscura, que acecha constantemente y pide manifestarse a través de su ser, genera un agotamiento de las energías vitales: "Yo soy el quién espeso, bastante cansado de desenterrar vedados atributos, / de labrarle los hombros macerados al agua del mar. / Cansado estoy, sí, quiero salvarme de lo que fatalmente ha de ser, sálvame mano velluda del monte eterno" (V, 22).

Aun cuando la facultad profética no se adquiere por voluntad propia, sino que se recibe sin ser pedida, sí implica un gran trabajo de parte de quien la posee. El esfuerzo sobrehumano que se requiere para soportar este destino se manifiesta metafóricamente como la carga de un peso: "Nada puede aligerar tus hombros del peso de la altura, ella miente para los que la imaginan demasiado" (VI, 25). Así sentencia el yo-otro, haciéndole entender al yo que el destino que le ha sido designado es ineludible. Respecto a lo expresado con relación a la altura, se puede entender que el don eleva al que lo posee, lo sitúa en un plano superior al terrenal. Sin embargo, el saberse elevado conlleva el riesgo de malversar el don, de caer en la tentación de identificarse con el conocimiento recibido. Esto se vincula con el siguiente punto a tratar: el de la sumisión y humildad requerida para realizar la tarea profética.

El poder que posee al hablante constituye una especie de castigo: aunque resulta ser un bien provechoso para los demás, para él solo trae dolor y sufrimiento: "Tu relámpago aclara a los que están de pie delante de la tierra, mas a ti te ciega porque proviene de ti, la luz que proviene del hombre tiene un lado ciego" (XIV, 54). La misión redentora del hablante, que evoca a las figuras de Prometeo y de Cristo, exige un sacrificio: como portador de una verdad trascendental, el yo debe inmolarse para cumplir con su misión. No solo entregar un mensaje, sino que en el proceso entregarse él mismo.

Cuando el yo asume que no hay forma de librarse de las fuerzas sobrenaturales que lo acometen, se hace necesario renunciar por completo a cualquier forma de autodeterminación, para entregarse definitivamente a esa voluntad otra: "Proclámame entre las criaturas como el que guarda la ley, como el que a fuerza de esperar se desencanta y ejecuta órdenes" (X, 40). Si bien en este pasaje el rol de ejecutor de un mandato superior es asumido con resignación, también hay otros momentos en que el sujeto manifiesta su ímpetu por responder valeroso al destino: "Retorna oh rueda inmensa, ola quiébrate en mí, aprendamos a doblar las rodillas enteras, a tomar por los nudos al corazón (...)" (XVIII, 65).

A modo de síntesis, más allá del ánimo con que el sujeto asume o no su misión de encarnar y dar cuenta de la dimensión misteriosa que lo asalta, la determinación final no está en sus manos. Aun cuando el yo decide entregarse a la voluntad del yo-otro y su naturaleza trascendente, este último se muestra antojadizo y no termina de manifestarse nunca por completo. Por una parte, incita al yo a acudir a su encuentro y, por otra, se oculta cuando este decide entregarse: 
Pero huye el fantasma que cierra tras de sí las puertas de mi origen; soy tan prudente con él, (...) soy apenas lo que sobrevive de tan doliente ser, su antojo terrenal, sus palmas diurnas que a veces bato sin que la causa sea mía, llevo su collar de cuero grabado que me distingue de toda otra hermandad (XI, 44).

A través de la imagen del collar, se refuerza el carácter de subyugado que cumple el yo frente a su yo-otro y la potencia sobrehumana que representa. En última instancia, el hablante no es más que un medio: se le dota de la visión para que él, a través de su palabra, sea capaz de expresar y transmitir lo percibido. Es por eso por lo que, a continuación, ahondaremos en la forma en que la propia palabra del yo y el rol mediador que cumple son caracterizados.

\subsection{La palabra y el oficio poético}

Ya dijimos que la ponderación negativa que el hablante hace de su don se debe principalmente a que este, en vez de presentarse como respuesta a sus interrogantes vitales y ayudarlo a alcanzar la plenitud, no hace más que agravar su estado de incertidumbre y aumentar el sufrimiento. El trabajo que se le pide llevar a cabo a través de la palabra, es decir, el cultivo de la poesía como revelación, no puede entonces resultar placentero. Por el contrario, es descrito como un quehacer árido y tormentoso:

Palabras imprudentes me soplan en el templo, le arranco los ojos a los cirios, manos oscuras pasan por mi alma atando sus cabos sangrientos.

Ah poetas de mi tiempo que con saliva ablandáis tiernas golondrinas de barro, meted el pie en estas arenas movedizas, escarbad en el templo, danzad en las esteras ardientes que os han tejido desde el principio del mundo (IX, 37).

Este es el único momento en todo el poema en que se hace mención explícita al oficio escritural, a través de la interpelación a los poetas. Esta conlleva una particular ponderación de la poesía: frente a la poética predominantemente ornamental y vacía que el sujeto percibe como imperante en su tiempo histórico — expresada a través de la imagen de las tiernas golondrinas de barro como piezas de artesanía, delicadas pero faltas de vida-, se plantea una forma mucho más radical de llevar a cabo el oficio. Escribir poesía es entrar en contacto con lo primigenio, con el ámbito de lo sagrado - "escarbad en el templo"Lo que hace el poeta es una tarea primordial, destinada a realizarse "desde el principio del mundo". El hecho de que el sujeto invite a los poetas a aproximarse a las arenas movedizas en que él se encuentra, permite suponer que él también está embarcado en la misma empresa; el también es poeta, pero uno consciente de la real responsabilidad que supone el oficio.

La palabra, entonces, es entendida por el hablante como el espacio que hace posible la manifestación de la naturaleza del ser del hombre, que es esencialmente contradictoria: en ella conviven y se debaten potencias antagónicas, que en su incansable lucha configuran 
la existencia. El sujeto experimenta la contradicción en su interior y busca resolverla al exteriorizarla en la palabra:

Nada puede hacer el hombre en estos lugares por su poder; en vano quiere rescatarse de los signos que noche a noche paran su alma en medio de la muerte.

¿De qué dulce linaje soy proscrito? ¿qué álamo blanco sube de mí como un dedo hacia lo inaccesible?

La casa vertiginosa se eleva por encima de mí. Oh dominio inhumano, ruta del destierro! De mi corazón sale una lira ardiendo! (VIII, 33).

En este punto surge una segunda dificultad, ahora impuesta por la palabra misma, que también ofrece una naturaleza dialéctica: devela velando, revela una verdad volviendo a cifrarla. Heidegger plantea que esta dialéctica es la esencia, la raíz que hace posible toda obra de arte. En ella "la verdad acontece como la lucha primordial entre el alumbramiento y la ocultación" (2014: 77) ${ }^{6}$. Es justamente este fenómeno el que aflige al sujeto poético de $E l$ blasfemo coronado, quien, al no aceptar la dimensión oscura e inexpresable que toda verdad conlleva, se lamenta por la esterilidad de su palabra.

Desde su perspectiva racional, lo dicho es tan solo un vislumbre incompleto de la verdad que se oculta tras los fenómenos que experimenta: "Creced sentidos y extremad cada uno vuestro fin; las cosas que me traéis son siglos derrumbados, resoplidos, aletazos que me llenan de aire pálido (...) ¿Compensa el engaño de las imágenes el lamento del que discierne su plenitud?" (XVIII, 66). Así, en la pregunta planteada en este pasaje, se vuelve a manifestar la desconfianza inicial en las facultades irracionales; se hace patente, una vez más, la disyuntiva vital entre razón y delirio, entre filosofía y poesía. Con ninguna se alcanza el cese del dolor. La poesía, evaluada desde la razón, es considerada un engaño, una especie de evasión y perpetuación de la oscuridad.

La tarea que se le pide llevar a cabo, entonces, es imposible. El sujeto confirma a cada nuevo intento la cortedad de su decir: "Cada escama del día que levanto con la uńa, cada raíz de la noche que mi cuerpo se ata entre las sábanas no alcanzan a hacer de mi canto sino un ademán" (XI, 43). Ante la frustración que le genera el no poder decir lo que quiere decir, el yo se cuestiona el sentido de seguir perpetuando la imposibilidad - "No animal ni dios me han hecho, entonces, para qué te ejercito oh adivinación estéril?" (XXII, 81)—y llega a plantearse la radical opción de callar. El silencio se vislumbra como gran solución, como cese del sufrimiento:

\footnotetext{
${ }^{6}$ Para el filósofo alemán, la obra de arte constituye una novedad radical en tanto no es representación del mundo sino apertura de uno nuevo, diferente al espacio-tiempo histórico en que la obra misma surge. En este sentido es que la obra de arte "no solo abre e ilumina un mundo al proponerse como nuevo modo de ordenar la totalidad del ente, sino que, además, el abrir e iluminar, hace que se haga patente este otro aspecto constitutivo de toda apertura de la verdad que la metafísica olvida, es decir, la oscuridad y el ocultamiento de que procede toda revelación. (...) Esto es lo que Heidegger llama conflicto entre mundo y tierra en la obra” (Vattimo 1998: 108).
} 
Hay un jardín en que los dioses cuchichean, suelen pintar un hijo de hombre y soltarlo para la doma entre grandes furias que lo piensan;

nuestro destino parte de un grito prolongado, si lográramos callarnos, la profundidad del mundo nos fuera tan innata (IX, 36).

El origen del mal del hombre es la palabra. Hasta antes de ese primer grito, prolongado hasta el presente, el hombre era una criatura sin conciencia, pensada por las diosas del destino. Desde que el lenguaje le dio la posibilidad de pensarse a sí mismo, de introducir una distancia entre su ser y el mundo, el hombre vaga solo con su destino a cuestas, sin terminar de comprenderlo. En este sentido, el silencio representa la posibilidad de reintegrarse al todo, de acabar con la diferencia a través del retorno a la inocencia original. Sin embargo, a pesar del deseo de callar y volver a ser uno con la Unidad, el sujeto poético no puede dejar de hablar. Si bien hasta aquí ha identificado como error humano el hecho de querer expresar lo inexpresable, el impulso que lo obliga a seguir diciendo es parte de la voluntad divina: “(...) vanas palabras pretenden henchir el ser secreto que nadie ha podido asir y un párpado vacío se pudre entre las flores. (...) Pero hablo, sin embargo, como llovizna sobre la lengua palabras vienen mandadas" (XI, 43). Llegamos aquí a un punto que se esbozó brevemente en el análisis del primer fragmento: los dioses hacen hablar al poeta para que este le restituya a la palabra su naturaleza original. Antes que medio de comunicación, antes que herramienta de transmisión de significados predeterminados, la palabra es acontecimiento.

En el lenguaje de la divinidad, palabra y acción son una misma cosa: el mundo es creado a través de la palabra. Ahora bien, aunque la palabra humana no esté dotada de ese poder divino, e inevitablemente instale una distancia entre hombre y mundo, sí tiene la posibilidad de presentarse como reflejo. Esta sería la cualidad esencial de palabra poética, que según la concepción zambraniana "es la luz que no trata de explicar ni apropiarse nada sino sólo proponerse a la visión (...): poner es de alguna forma retraer algo del conjunto en el que se hallaba inmerso" (Maillard 1992: 35). Reflejo, entonces, no como mímesis, sino como recreación. Del reconocimiento de este fenómeno da cuenta el hablante en el fragmento que cierra el texto:

(...) cantores de los pueblos y gente que baila hecha de instantes puros conmigo súbitamente comprenden lo que nos es dado comprender.

Ah vida cómo cantarte! en tus formas eternas me arrojo y destruyo el número y la esencia y estoy alegra de ser mortal y espero la corona del mediodía profundo! (Epílogo del poema 99).

Cuando el yo acepta con humildad su oficio y se contenta con entregar lo que le es dado entregar en su limitada condición de ser humano, surgen momentos de plenitud, de experimentación genuina de su pertenencia a la tierra: "¿Entiendes el pacto carnal que somos, cuerpo hermoso y también profético? reduce entonces a carne los cielos, tiéndete entre las bestias 
del campo" (XXIV, 87). Aunque este estado no es nunca definitivo y el yo no deja nunca de oscilar entre la angustia que produce incertidumbre y la posibilidad de entregarse gozoso al misterio que constituye la existencia, sí se dibuja claramente al menos la intención de encaminarse hacia la integración de sus dos dimensiones, hacia la aceptación de su naturaleza dual.

\section{CONCLUSIONES Y PROYECCIONES}

La gran disyuntiva a la que se ve enfrentado el sujeto poético de El blasfemo coronado puede ser interpretada como la crisis del pensamiento moderno en su afán sistematizador y absolutista. Como apareció a lo largo del análisis, las dos dimensiones irreconciliables que constituyen al hablante, y que nosotros identificamos con las figuras del filósofo y el poeta, pueden extrapolarse a la problemática que plantea el surgimiento del romanticismo a finales de siglo XVIII y principios del XIX en contra del paradigma ilustrado. La representación racionalizadora de la realidad que se impone durante el Siglo de las Luces supone una progresiva desacralización del mundo, la relegación y pérdida de la dimensión intuitiva y religiosa del ser humano. Frente a esta precarización espiritual, el romanticismo surge como impulso que recupera y revivifica la experiencia mítica.

En este sentido, el drama existencial que articula el poema parece responder a una cosmovisión ya en retirada, desfasada en el tiempo. El contexto de producción de la obra, primera mitad de siglo XX, corresponde al surgimiento y desarrollo de las vanguardias históricas, las que si bien, como plantea Paz (1974), representan "una continuación de la tradición iniciada por el romanticismo" (159), en tanto tradición de la ruptura, surgen como necesidad de cambio y responden a unas problemáticas vitales nuevas, hijas del vértigo de "la era de las concentraciones multitudinarias en las ciudades fabriles, era de las comunicaciones rápidas, de las circulaciones internacionales, de la incorporación de las regiones más remotas al nuevo orden ahora realmente mundial" (Yurkievich 1982: 351). La innovación y experimentación formal que caracterizan a la vanguardia, así como su incorporación "de lo sólito, lo local, lo pedestre, de lo crudamente psicosomático, de lo incidental y lo accidental en sus mezcolanzas antitéticas, del hombre en su circunstancia" (353), son elementos que no encontramos en El blasfemo coronado.

Por el contrario, en cuanto al tratamiento temático, el tono y ánimo del hablante, el poema en prosa de Díaz-Casanueva presenta un temperamento mucho más cercano a la poesía romántica que a cualquier poética contemporánea. Por una parte, la disputa de la verdad que se despliega entre el yo con sus inquietudes filosófica y el yo-otro con su potencial mágico-poético, tiene su raíz en el romanticismo alemán, tradición que se ha reconocido como una de las influencias y fuentes de diálogo importantes que el poeta chileno incorpora a su escritura. Como precisa Casullo, "el romanticismo germano tiene una (...) obsesión por lo filosófico poético. Por desentrañar a partir de ese cruce, culturalmente, el enigma de lo moderno" (1999: 278-279). Y no es otro el eje articulador de El blasfemo sino la lucha por alcanzar la síntesis entre aquellas dos maneras de aproximarse a la realidad y aprehenderla. 
El universo poemático de Díaz-Casanueva está orientado a crear, en términos de Paz (1974), su propia mitología del poeta, lo que también se reconoce como empresa propiamente romántica: "cada poeta inventa su propia mitología y cada una de esas mitologías es una mezcla de creencias dispares, mitos desenterrados y obsesiones personales" (70). Así sucede en el caso de El blasfemo coronado, en el que se reconocen una serie de elementos procedentes de diferentes épocas y culturas, entre las que destacan la tradición cristiana y la mitología griega. Si bien no nos abocamos a tratar esos aspectos en este trabajo, nos limitamos ahora a seńalar algunos de ellos y a plantearlos como materia a estudiar en una eventual continuación y ampliación del análisis. Con relación al imaginario cristiano, identificamos la metáfora del pastor y las ovejas, la figura de la Mujer-Virgen, y el sentido de culpa. En cuanto al mundo griego, la oposición entre lo apolíneo y lo dionisiaco, el mito de Prometeo y la existencia de un destino urdido por potencias superiores, en este caso Las Furias.

A pesar de lo anterior, un aspecto en que el poemario sí se diferencia de la cosmovisión romántica y revela las condiciones propias del contexto histórico en que surge, es el carácter predominantemente pesimista del sujeto frente a esa otra dimensión trascendente que se presenta como posibilidad conciliadora de los opuestos. Si bien el yo tiende permanentemente hacia ese ideal, la plenitud y el cese de las contradicciones nunca se concretan. En este sentido, la inviabilidad del don profético y de la palabra deja en evidencia el escepticismo y negatividad imperantes en la producción artística de primera mitad de siglo XX. Esta actitud alcanza su máxima expresión con la desarticulación radical de la organización formal durante las vanguardias. Como expresa Yurkievich, "la escritura se agita y se fisura, todo perfilamiento es quebrado por los ritmos frenéticos, (...) por una exasperación que no tolera detenimientos, que impide toda conclusión retórica, que somete la obra de arte a perpetuo inacabamiento" (1982: 353). Aunque en El blasfemo coronado nunca se llega a este extremo, sí se produce una lucha a nivel lingüístico que, propiciada por la prosa, amenaza permanentemente con la imposibilidad de construir un sentido.

La tensión mencionada es una cualidad propia del poema en prosa, que oscila entre dos actitudes: "la organización artística y la anarquía destructiva" (Utrera 1999: 11). De esta forma, la influencia del romanticismo con su anhelo de armonía, no se presenta como único horizonte de posibilidad del texto, sino que esa aspiración a la unidad es concebida como uno de los dos extremos entre los que se vacila dentro del espacio dialéctico que constituye el poema en prosa. Ambos polos, armonía y anarquía, encuentran su punto de equilibrio en el ejercicio crítico, que no es destrucción sino deconstrucción. La conciencia analítica instala la crisis al dejar en evidencia las fisuras del lenguaje en su intento de aprehensión de la verdad y de la organización de un todo armónico: "con palabras nombro esto o aquello como en subasta entre taciturnos, ni siquiera las luces que crío pueden libertarme (...) Ah ciencia corrompida que ejercito sin vigor" (Díaz-Casanueva 1981: XI, 43-44). Ahora bien, la toma de conciencia de las limitaciones de su lenguaje, le abren al mismo tiempo la posibilidad al hablante de superar esa imposibilidad, ya que al manifestar que lo que pretende decir es indecible, hace que eso indecible quede dicho como posibilidad latente. 
Este es un tema que seguirá apareciendo en los siguientes poemarios de DíazCasanueva y que podemos situar dentro de una corriente poética y de pensamiento que, en sintonía con los planteamientos de Heidegger (con quien tomó clases durante su estancia en Alemania), concentra sus reflexiones en la palabra y su valor ontológico. A partir la afirmación de que "el lenguaje es la sede, el lugar en que acontece el ser" (Vattimo 1998: 113) y del reconocimiento de la relación de recíproca determinación hombre-ser que se lleva a cabo en la palabra, Díaz-Casanueva desarrolla una poesía volcada a plasmar, escudriñar y tantear los límites de esa experiencia. Una proyección del trabajo en esta dirección, entonces, es la de ahondar en la forma en que esta inquietud ontológica, que reconocemos comienza a manifestarse en El Blasfemo coronado y antes en Vigilia por dentro, se radicaliza en los poemarios posteriores y toma un lugar cada vez más protagónico.

\section{Obras Citadas}

Aullón de Haro, Pedro. 2005. “Teoría del poema en prosa”. Quimera 262: 22-25.

Casullo, Nicolás. 1999. "El romanticismo y la crítica de las ideas”. En Nicolás Casullo, Ricardo Forster y Alejandro Kaufman, eds., Itinerarios de la modernidad. Buenos Aires: Eudeba. 273-297.

Darío, Rubén. 2009. “[¡Torres de Dios!_Poetas!...]”. En Ricardo Gullón, ed., Páginas escogidas. Madrid: Cátedra. 105.

Del Valle, Rosamel. 1959. La violencia creadora: poesía de H. Díaz-Casanueva. Santiago: Panorama.

Díaz-Casanueva, Humberto. 1981. El blasfemo coronado. México: Oasis.

Foxley, Carmen. 1998. "Prólogo. Lectura interpretativa y diferencial en la obra de Humberto Díaz-Casanueva”. En Vigilia por dentro. Réquiem. Los penitenciales. Santiago: Universitaria. 17-49.

Guezález, Miguel. 1949. "Poesía y metafísica en Diaz Casanueva”. Revista Atenea 289: 93100.

Heidegger, Martin. 2014. Arte y poesía. México: Fondo de Cultura Económica. 33-104.

Jiménez Arribas, Carlos. 2005. "Estudios sobre el poema en prosa". Signa: revista de la Asociación Española de Semiótica 14: 125-144.

Jiménez, José Olivio. 1981. "Hacia el pensamiento poético de Humberto Díaz-Casanueva”. Hispamérica 30: 83-98.

Maillard, Chantal. 1992. La creación por la metáfora. Introducción a la razón poética. Barcelona: Anthropos.

Millán Alba, José. 1989. "Algunos aspectos del poema en prosa y las categorías del lirismo contemporáneo". En Francisco Lafarga, ed., Imágenes de Francia en las letras hispánicas. Barcelona: Promociones y Publicaciones Universitarias. 29-36.

Millares, Selena. 2008. El fuego y la fragua: ensayo de literatura comparada. Salamanca: Ediciones Universidad de Salamanca. 
Minard, Evelyn. 1988. La poesía de Humberto Díaz-Casanueva. Prólogo de Saúl Yurkievich. Santiago: Editorial Universitaria.

Nómez, Naín. 1992. "Humberto Díaz Casanueva". Poesía chilena contemporánea: breve antología crítica. Santiago: Fondo de Cultura Económica. 193-202.

Ortega, Juan Fernando. 2007. "Introducción. La unidad de filosofía y poesía en María Zambrano". Algunos lugares de la poesía. Por María Zambrano. Madrid: Trotta. 9-29.

Paz, Octavio. 1974. Los hijos del limo. Barcelona: Seix Barral.

Rojas, Waldo. 1992. "Humberto Díaz-Casanueva: Refulgencias y relecturas. Reconocimiento y revelación". Revista chilena de Literatura 35: 37-62.

Schwitzer, Alan. 1967. "El blasfemo coronado de Humberto Diaz-Casanueva". Atenea 418: 1791-187.

Utrera, María Victoria. 1999. Teoría del poema en prosa. Sevilla: Universidad de Sevilla.

Vattimo, Gianni. 1998. "Ser, evento, lenguaje". Introducción a Heidegger. Barcelona: Gedisa. 93-126.

Yurkievich Saúl. 1982. "Los avatares de la vanguardia". Revista Iberoamericana 118-119: 351-366.

Zambrano, María. 2013. Filosofía y poesía. México: Fondo de Cultura Económica. 